women from all forms of cancer show widely differing trends. In a little over a decade, the age adjusted rates have fallen in seven countries, increased in four and remained stationary in two (see Table). The largest declines in death rates from cancer were among American white women, Norwegian women and American non-white women, and the largest increases in rates were in Israel, Denmark and Japan. Japanese and Australian women seem to have the least chance of dying from cancer whereas Danish women have the highest chance. Does this mean that there is a very much greater risk in the Danish way of life, or are the diagnoses made and statisties kept in Denmark more reliable? This question clearly bedevils any comparison between countries. In the United States, on the other hand, the striking difference between cancer deaths among white and non-white women no doubt reflects the better social and economic position of the former rather than inherent racial tendencies.

Deaths from cancer of the digestive organs have declined in most countries, but the wide variations in the statistics suggest that they are not very reliable and there is, of course, great difficulty in diagnosing the primary site of cancer in these organs. In all countries, however, deaths from lung cancer have predictably increased, as have deaths from leukaemia. In Japan, the leukaemia death rate increased by 125 per cent in the decade, but the country still has the lowest rate, which suggests that previously undiagnosed deaths are now being included. Whether the increased rates of death from leukaemia in general are real or just the result of better diagnosis is an open question. What does seem certain is that deaths from uterine cancer are decreasing and much of this reduction can be attributed to early detection and treatment. In the United States, however, despite the large decline of uterine cancer in non-white women, death among them is still twice that among white females and well above that of any of the other countries in the survey. Undoubtedly these deaths could be prevented by adequate medical services. There has, however, been no real progress in reducing deaths from breast cancer in any of the countries in the survey.

\section{No Education without Representation}

So far, student unrest in Britain has not begun to rival the stirring events in other parts of the world. Only the University of Essex and the London School of Economics have suffered the kinds of disturbances which have been widespread in the United States, France and West Germany. British students have retained their reputation for stolidity, and the National Union of Students, devoted to gradualism, can still claim the loyalty of the majority. But in the universities this week there seems to have been no feeling of self-congratulation, but rather of relief tempered by concern that more should be done soon to make students feel involved in the organization of their universities.

The immediate way in which this can be done is by appointing students to university committees, a process which was launched in Britain by the trouble at LSE, and now seems well under way. At the University of Sussex at Brighton, for example, disciplinary problems are dealt with by a committee on which students are in a majority. The committee has an investigatory function, and the vice-chancellor remains responsible for determining the punishment. Experience seems to suggest that students are unexpectedly severe on their fellows, and the staff members of the committee find themselves trying to counteract this. The latest development at Sussex is the establishment of an appeals procedure to give students the right of appeal against disciplinary decisions. This committee will include student representatives.

Elsewhere similar developments are taking place, and the new universities are well to the fore. Two former colleges of advanced technology, now the City University and the University of Bradford, are said to be particularly forward looking. Disciplinary problems are generally thought to be the most urgent, but other universities are also thinking of introducing student representatives on to academic and administrative committees. One of the difficulties seems to be that students are ignorant of the ways their own universities are run, and there have been cases where students have turned down arrangements which would in fact have offered them more effective power than they were asking for, simply because they did not understand what was being offered. In some cases liberal vicechancellors have had to push through changes in organization against the opposition of their governing bodies, who tend to be less willing to involve students in university government.

Other academics suggest that this process alone will do little to remove the causes of unrest. There is the suggestion, for example, that the appointment of a few students to a committee will make those fow feel happier, but will leave the rest as detached as ever from university government. There is also some pressure in the universities to reduce rather than increase the number of committees, in the hope of improving university "productivity". There comes a point, one university scientist argued this week, when the claims of efficiency have to give way to humanity. A balance must be struck between the need of the students - and the staff-to feel involved, and the need to avoid the proliferation of committees which have no real function to perform.

But it is still not clear that this gentle process of democratization will be enough to satisfy student aspirations. The consensus seems to be that there will always be a small minority (particularly, some say, at universities with large social science departments) who will never be satisfied with less than a full-blown cultural revolution. The great majority, though, will be happy with very much less. This is probably a realistic assessment. Only a radical change of educational policy, such as the replacement of student grants by loans, would turn a sizable part of the British student population into radicals. Until that happens, the National Theatre is unlikely to be stormed by a student army.

\section{Technology in School}

The Schools Council subscribes to the belief that it is important to introduce technology to school children, both for their own benefit in helping them to understand the increasingly complicated environment and to encourage them to take up scientific or technological careers. These conclusions emerged from a pilot project in 1966 which investigated the technological activities in sixty schools, and a three-year project was set up in 